\title{
Article \\ Experimental Investigations on Dry Sliding Wear Behavior of Kevlar and Natural Fiber-Reinforced Hybrid Composites through an RSM-GRA Hybrid Approach
}

\author{
Banu Murali ${ }^{1, *}$, Bindu Madhavan Vijaya Ramnath ${ }^{2}$, Devaraj Rajamani ${ }^{1}$ (D) Emad Abouel Nasr ${ }^{3}$ (D), \\ Antonello Astarita ${ }^{4}$ (D) and Hussein Mohamed ${ }^{5,6}$
}

Citation: Murali, B.; Vijaya Ramnath, B.M.; Rajamani, D.; Nasr, E.A.;

Astarita, A.; Mohamed, $\mathrm{H}$.

Experimental Investigations on Dry Sliding Wear Behavior of Kevlar and Natural Fiber-Reinforced Hybrid Composites through an RSM-GRA

Hybrid Approach. Materials 2022, 15, 749. https://doi.org/10.3390/ ma15030749

Academic Editor: Ricardo J. C. Carbas

Received: 5 December 2021

Accepted: 12 January 2022

Published: 19 January 2022

Publisher's Note: MDPI stays neutral with regard to jurisdictional claims in published maps and institutional affiliations.

Copyright: (c) 2022 by the authors. Licensee MDPI, Basel, Switzerland. This article is an open access article distributed under the terms and conditions of the Creative Commons Attribution (CC BY) license (https:// creativecommons.org/licenses/by/ $4.0 /)$.
1 Department of Mechanical Engineering, Vel Tech Rangarajan Dr. Sagunthala R\&D Institute of Science and Technology, Chennai 600062, India; rajamanitamil1991@gmail.com

2 Department of Mechanical Engineering, Sri Sairam Engineering College, Chennai 600044, India; vijayaramnath.mech@sairam.edu.in

3 Department of Industrial Engineering, College of Engineering, King Saud University, Riyadh 11421, Saudi Arabia; eabdelghany@ksu.edu.sa

4 Department of Chemical, Materials and Industrial Production Engineering, University of Naples Federico II, 80138 Naples, Italy; antonello.astarita@unina.it

5 Department of Mechanical Engineering, Faculty of Engineering, Helwan University, Cairo 11732, Egypt; hussein@h-eng.helwan.edu.eg

6 Mechanical Engineering Department, Faculty of Engineering, Ahram Canadian University, Giza 8655, Egypt

* Correspondence: muralimech.b@gmail.com

\begin{abstract}
The present work aimed to investigate the dry sliding wear behaviors of hybrid polymer matrix composites made up of Kevlar, bamboo, palm, and Aloe vera as reinforcement materials of varying stacking sequences, along with epoxy as the matrix material. Three combinations of composite laminates with different stacking sequences such as $\mathrm{AB}, \mathrm{BC}$, and $\mathrm{CA}$ were fabricated by a vacuum-assisted compression molding process. The influence of composite laminates fabricated through various stacking sequences and dry sliding wear test variables such as load, sliding distance, and sliding velocity on the specific wear rate and co-efficient of friction were investigated. Experiments were designed and statistical validation was performed through response surface methodology-based D-optimal design and analysis of variance. The optimization was performed using grey relational analysis (GRA) to identify the optimal parameters to enhance the wear resistance of hybrid polymer composites under dry sliding conditions. The optimal parameters, such as composite combinations of CA, a load of $5 \mathrm{~N}$, a sliding velocity of $3 \mathrm{~m} / \mathrm{s}$, and a sliding distance of $1500 \mathrm{~m}$, were obtained. Furthermore, the morphologies of worn-out surfaces were investigated using SEM analysis.
\end{abstract}

Keywords: hybrid polymer composites; dry sliding wear behavior; D-optimal design; grey relational analysis; surface morphology; optimization

\section{Introduction}

Bio-resources such as plant, bast, and core are widely used as natural fibers in the present manufacturing scenario for the development of novel structural materials for various high-end applications such as in the automobile, aerospace, marine industries and bioelectronics. In general, biologically derived fibers are significantly used due to their easily degradable quality and their rejuvenation of bio-active chemicals from natural processes [1]. Moreover, naturally derived fibers are more efficient than other commercial chemical fibers due to their lower density, non-abrasive manner, enhanced acoustic properties, adequate explicit modulus and strength, cost effectiveness, easy biodegradability, and efficient re-cycle capability, which improve the characteristics of natural fibers [2-6]. 
Despite their potential benefits, the inferior mechanical strength, moisture absorption, and chemical affinity of natural fibers mean they are cumbersome in practical implications [7-9]; hence, the hybridization of synthetic fibers with biological fibers is required to improve the mechanical properties and durability of composites [10]. Synthetic and natural fibers can be merged into an equal matrix to yield hybrid composites that take complete advantage of the finest assets of the ingredients, and in this way, an optimal cost-effective composite can be developed.

In recent years, global researchers have increased their attention on using castoff synthetic fiber resources, including glass, carbon, aramid, and other types of polymer fibers, due to their incline in the ecological risk of pollution and removal of waste at the end of life. Surplus synthetic fibers are richly available from diversified sources, including polymer fibers, glass, fabric clippings in composites, and textile industry waste [11]. Hybrid polymer matrix composites (HPMCs) are extensively utilized in delicate body shells, ballistic helmets, and several other ballistic applications [12-14]. The mechanical, dynamic, and tribological properties of hybridized polymer matrix composites can be enhanced through several matrix and reinforcement materials, fabrication techniques, and additions of various filler materials $[15,16]$ to increase the use of HPMCs in a wide range of technological applications, especially in the high loading and relation motion of assembling parts. Due to the relative motion under various loading conditions, it is desirable to improve the tribological performance of composites, so that they can be effectively used for practical applications. Recently, several researchers have studied the influence of various fabrication techniques, fiber and matrix materials, and inclusion of filler materials on tribological properties such as the wear resistance of HPMCs.

Sneha Latha et al. [17] studied the effect of various woven fiber mat layering sequences in bamboo/glass fiber-reinforced hybrid composites, showing highly influenced wear behavior. An increase in the amount of glass fiber in the hybrid composites showed better mechanical properties. Similarly, increasing the amount of bamboo fiber in the hybrid composites resulted in better wear resistance, which was due to the strong interfacial bond strength between the fibers and fiber matrix. A proper combination of glass and bamboo fibers can produce hybrid composites with better mechanical properties and tribological behavior. Thus, the achievement of hybrid composites with better properties upon addition of bamboo fiber generates scope for cost reduction without compromising the quality of composites. Nevin Gamze et al. [18] investigated the performance of short fibrous composites on various parameters such as fiber alignment, length, and loading. In the fabrication process, long fibers were exposed to high-temperature shear action due to the interaction with thermoplastic resin, and this caused the fiber to twist, followed by a reduction in length. The influence of fiber matrix interfacial adhesion and test operating variables such as applied load, sliding distance, and velocity plays a major role in calculating the strength and tribo-performance of composites. Hiral et al. [19] listed the various disadvantages of using synthetic fibers for reinforcement, such as the biodegradability of fibers, high processing cost, recyclability, and health hazard. These issues can be tackled by using natural fibers as an alternative to synthetic fibers, providing an advantage in terms of the strength-to-weight ratio, ease of availability, and biodegradability. From the test results, they concluded that the hybrid basalt banana epoxy composite is a good substitute over various conventional materials, and that hybridization reduces the water absorption rate. Shuhimi et al. [20] experimentally investigated the tribological characteristics of oil palm and kenaf fiber with epoxy resin as the medium, and both composites were compared. A pin-on-disk test was administered to work out the wear behavior, and a dry sliding test was performed using a pin-on-disk tribometer. Test parameters such as weight percentage of fiber, load, sliding speed, and temperature ranges were taken as the operational parameters. The results showed that an increase in temperature resulted in a decreased coefficient of friction and an increased wear rate for both composites. The wear rate for both fibers exhibited better performance by increasing the fiber content. 
From the literature, it can be inferred that several researchers have studied the tribological properties of HPMCs through experimental studies and the adoption of several statistical approaches. However, investigations pertaining to the tribological properties of a combined Kevlar, bamboo, Aloe vera, and palm-reinforced epoxy matrix composite with different stacking sequences have not been conducted by any researchers. Therefore, the present work aimed to investigate the tribological properties, such as the specific wear rate $(S W R)$ and the coefficient of friction $(C O F)$, of various stacking sequence, such as aloe vera and bamboo $(\mathrm{AB})$, bamboo and palm $(\mathrm{BC})$, and palm and aloe vera $(\mathrm{CA})$, with alternate layers of Kevlar-reinforced polymer matrix composites. The composite laminates were fabricated through a custom-developed vacuum-assisted compression-molding process and the wear characteristics of different stacking-sequenced HPMCs were investigated through a dry sliding wear testing apparatus with varying loading conditions, such as applied load, sliding velocity, and sliding speed. The wear test experiments were designed and executed through a categoric factored response surface methodology-based D-optimal design. The statistical validation of the proposed experimental approach was evaluated through a multiple-variable analysis of variance (ANOVA) and normal probability residual plots. The influence of various dry sliding parameters and composite combinations on the tribological properties were studied using three-dimensional response surface plots. The optimal wear testing parameters and the composite combinations were obtained through adopting the grey relational analysis approach. Furthermore, the surface modifications of dry sliding worn out surfaces were investigated through scanning electron microscopic analysis.

\section{Proposed Methodology}

\subsection{RSM-Based D-Optimal Design}

A well-organized experimental strategy can significantly influence the consequences and outcomes of experimental results. Among the several designs of experiments approaches, response surface methodology is one of the most widely used approaches for designing and executing experiments with minimal runs for novel engineering applications. In the present study, a response surface methodology (RSM)-based D-optimal design methodology was utilized to plan experiments with minimal runs [21]. The scheme of the present study utilized three numerical factors associated with wear testing and one categoric factor, i.e., different composite combinations. According to the experimental strategy, a three-level and four-factor experiment of design with a total of 28 experiments were designed. The selected parameters and their associated levels are listed in Table 1.

Table 1. Process variables with their levels used for dry sliding wear tests.

\begin{tabular}{cccccc}
\hline No & Process Variables & Unit & $\mathbf{- 1}$ & Levels & $\mathbf{0}$ \\
\hline 1 & Applied load & $\mathrm{N}$ & 5 & 10 & 15 \\
2 & Sliding velocity & $\mathrm{m} / \mathrm{s}$ & 1 & 2 & 3 \\
3 & Sliding distance & $\mathrm{m}$ & 500 & 1000 & 1500 \\
4 & Composite combination & Categorical & $\mathrm{AB}$ & $\mathrm{BC}$ & $\mathrm{CA}$ \\
\hline
\end{tabular}

\subsection{Grey Relational Analysis (GRA)}

GRA is a statistical optimization methodology that can be conceived for solving complex real-world problems with inferior, inadequate, and indeterminate data sets [22]. GRA is utilized to resolve the multifaceted correlation that exists between the multiple response features of a process. The grey theory consists of two data sets, in which unidentified and well-known data are defined as "black" and "white" systems, respectively, whereas partially defined data are defined as "grey" systems.

The present investigation concentrated on the dry sliding wear behaviors, such as SWR and COF, which were initially standardized from zero to one. In this case, the selected response features should be minimized to improve the wear resistance of fabricated hybrid composites. Therefore, the characteristics of the optimization problem were proposed 
as "the lower, the better". The responses of the present study were minimized by the normalization process, as mentioned by the following equation:

$$
S_{i}^{*}(n)=\frac{\max _{i}(n)-S_{i}(n)}{\max S_{i}(n)-\min S_{i}(n)}
$$

To achieve a considerable objective, the normalized data were standardized using the following relation:

$$
S_{i}^{*}(n)=1-\frac{\left|S_{i}^{o}(n)-S^{o}\right|}{\max _{i}^{o}(n)-S^{o}}
$$

The grey relational coefficient (GRC) is defined as the relationship factor between the experimental standardized data and the actual data. The GRC can be calculated using the following expression:

$$
\xi_{i}(n)=\frac{\Delta_{\min }+\xi \Delta_{\max }}{\Delta_{o i}(n)+\xi \Delta_{\max }}
$$

where the deviation of the reference sequence order is indicated as $\Delta_{o i}$ and the comparability sequence is indicated by $\Delta$ max.

$$
\begin{aligned}
& \Delta_{o i}=\left\|S_{o}^{*}(n)-S_{i}^{*}(n)\right\| \\
& \Delta_{\min }=\min _{\forall j \ni i} \min _{\forall k}\left\|S_{o}^{*}(n)-S_{j}^{*}(n)\right\| \\
& \Delta_{\min }=\max _{\forall j \ni i} \max _{\forall k}\left\|S_{o}^{*}(n)-S_{j}^{*}(n)\right\|
\end{aligned}
$$

where the reference order is $S_{o}^{*}(n)$ and $S_{i}^{*}(n)$ indicates the comparability order. The identification factor is defined by $\xi$. The grey relational grade (GRG) is calculated by:

$$
\gamma_{i}=\frac{1}{m} \sum_{n=1}^{m} \xi_{i}(n)
$$

where the number of total experimental trials is indicated as $m$, and the GRG is indicated as $\gamma_{i}$, which lies between zero to one.

\section{Experimental Details}

\subsection{Materials}

Aramid is an acronym for aromatic polyamide (poly-p-phenylene terephthalamide), often known as Kevlar, which is the most widely used synthetic fiber in the fabrication of components for aerospace and structural applications. Many compostable and biodegradable fibers produced from plants have also been used as reinforcement components in polymer for the production of sophisticated composites by researchers. Natural fibers such as aloe vera, bamboo, and palmyra palm, and Kevlar fiber with densities of 1.4, 0.9, 1.3, and $1.43 \mathrm{~g} / \mathrm{cm}^{3}$ were employed in a predetermined stacking sequence to fabricate the hybrid composites in this study. The matrix material was formed of epoxies (LY556) and hardeners (HY951) with densities of $1.15-1.20 \mathrm{~g} / \mathrm{cm}^{3}$ and $0.97-0.99 \mathrm{~g} / \mathrm{cm}^{3}$, respectively. Kevlar fibers were used as the outer skin of the fabricated composite to enhance the surface quality and strength. The weight ratio of the mixing epoxy and hardener was 10:1 to provide adequate interfacial bonding between fibers.

\subsection{Fabrication of Composites}

The composite laminates for the present investigation were fabricated through a vacuum-assisted compression molding process due to its prominent benefits over other conventional processing techniques. The composite specimens were fabricated with five layers, in which the outer and middle layers were made up of Kevlar fiber and the other layers, such as each second and fourth layer, were made up of Aloe vera, bamboo, and palm 
fibers. The stacking sequence of the fibers for different composite laminates are shown in Figure 1, and the same is presented in Table 2. For each hybrid composite, the ratio of fibers to the polymer matrix was taken as 60:40. In this proposed vacuum-assisted compression molding process, the downsides of different techniques were overwhelmed by making a vacuum inside the shape, with the goal that an air trap could not be framed inside the composite. The phases of fabricating composite laminates through the proposed approach are presented in Figure 2a-c. In the first stage of fabrication, a shield (mold box), along with a vacuum pump and an MS steel pattern, was prepared with the prescribed shape in which the composite was fabricated. In the wake of framing the necessary blend, the shape was permitted to dry for $5 \mathrm{~h}$, and afterward, the manufactured composite overlay was launched out from the mold. After the composite laminates had solidified, the unpleasant edges were ejected and cut according to the required dimensions.

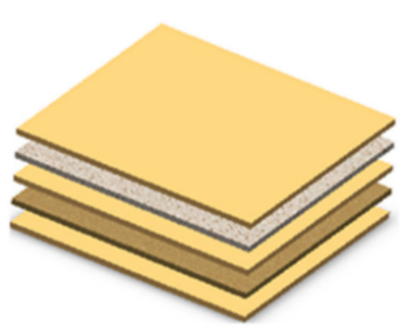

AB

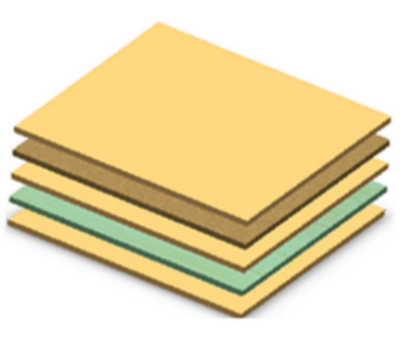

BC

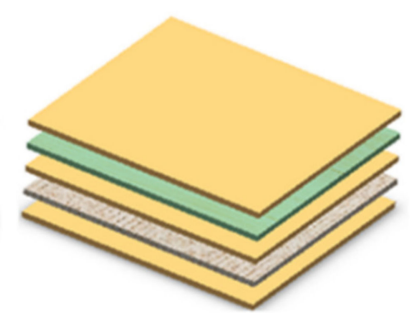

CA

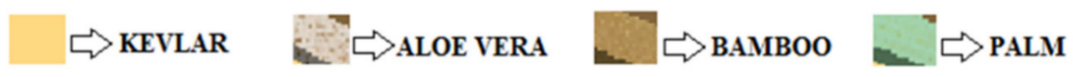

Figure 1. The configuration of composites fabricated with varying stacking sequences.

Table 2. Proposed stacking sequence of composite laminates.

\begin{tabular}{ccc}
\hline D1 (AB) & D2 (BC) & D3 (CA) \\
\hline Kevlar & Kevlar & Kevlar \\
Aloe vera & Bamboo & Palm \\
Kevlar & Kevlar & Kevlar \\
Bamboo & Palm & Aloe vera \\
\hline Kevlar & Kevlar & Kevlar \\
\hline
\end{tabular}

\subsection{Wear Test and Measurement}

According to the RSM-based D-optimal experimental strategy, the fabricated composite laminates $(\mathrm{AB}, \mathrm{BC}$, and $\mathrm{CA})$ were machined to obtain test samples for wear testing with appropriate dimensions (6 $\mathrm{mm}$ diameter and $24 \mathrm{~mm}$ length). The experiments were performed using a pin-on-disk setup (Model: Ducom-TR-20LE) to obtain the wear characteristics. To obtain the wear characteristics, the counterface disk (100 mm diameter) was made up of a highly hardened die steel with a hardness value of 62 HRC. As per the experimental strategy, a total of 28 experiments were performed to attain the SWR and COF values. The $S W R$ of the test specimens was assessed through the following relation:

$$
\operatorname{SWR}\left(\mathrm{mm}^{3} / \mathrm{Nm}\right)=\frac{\text { Loss of volume }}{\text { Sliding distance } \times \text { Load }}
$$

The coefficient of friction for each experimental trial was directly obtained from the wear testing apparatus. The response values were assessed thrice for each experiment to avoid measuring errors, and their corresponding values are presented in Table 3. 


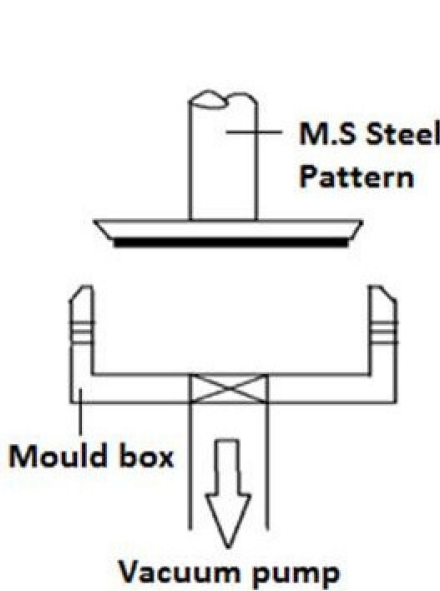

(a)

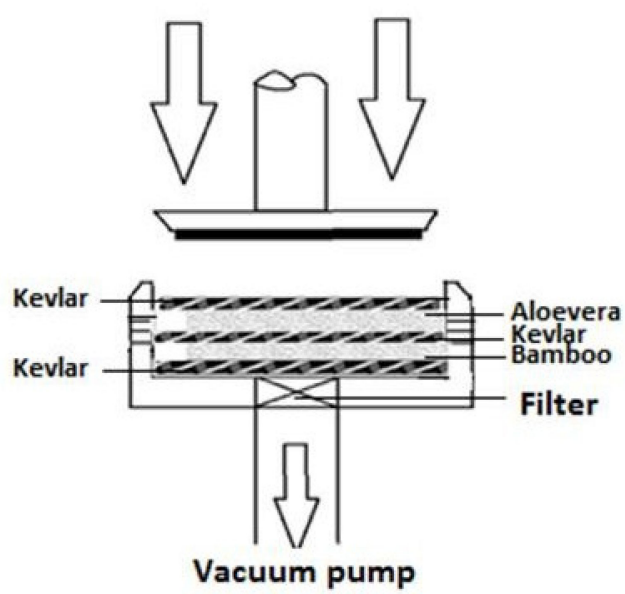

(b)

\section{Exteral Pressure Applied}

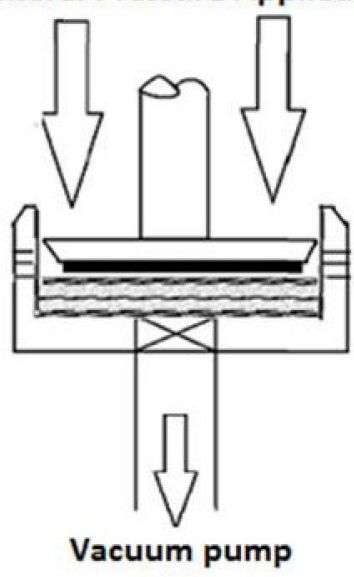

(c)

Figure 2. Schematic of vacuum-assisted compression molding for the fabrication of hybrid composites: (a) Mold and pattern; (b) arrangements of prepregs in the mold; (c) compression of prepregs with external pressure.

Table 3. Experimentally measured SWR and COF for the composite specimens.

\begin{tabular}{|c|c|c|c|c|c|c|}
\hline Exp No. & $\begin{array}{l}\text { Applied } \\
\text { Load (N) }\end{array}$ & $\begin{array}{c}\text { Sliding } \\
\text { Velocity } \\
(\mathrm{m} / \mathrm{s})\end{array}$ & $\begin{array}{l}\text { Sliding } \\
\text { Distance } \\
\text { (m) }\end{array}$ & $\begin{array}{l}\text { Sequence of } \\
\text { Composite } \\
\text { Laminates }\end{array}$ & $\begin{array}{c}S W R \\
\left(\mathrm{~mm}^{3} / \mathrm{N}-\mathrm{m}\right)\end{array}$ & $\mathrm{COF}$ \\
\hline 1 & 10 & 3 & 500 & $\mathrm{AB}$ & $3.82 \times 10^{-7}$ & 0.323 \\
\hline 2 & 15 & 2 & 1000 & $\mathrm{AB}$ & $9.43 \times 10^{-7}$ & 0.354 \\
\hline 3 & 15 & 1 & 1500 & $\mathrm{BC}$ & $1.81 \times 10^{-7}$ & 0.266 \\
\hline 4 & 15 & 1 & 500 & CA & $4.50 \times 10^{-7}$ & 0.318 \\
\hline 5 & 15 & 3 & 500 & $\mathrm{BC}$ & $2.72 \times 10^{-7}$ & 0.357 \\
\hline 6 & 15 & 2 & 1500 & CA & $2.10 \times 10^{-7}$ & 0.268 \\
\hline 7 & 15 & 3 & 1000 & CA & $7.43 \times 10^{-8}$ & 0.316 \\
\hline 8 & 10 & 1 & 1500 & $\mathrm{AB}$ & $3.73 \times 10^{-7}$ & 0.285 \\
\hline 9 & 10 & 1 & 1500 & $\mathrm{AB}$ & $3.14 \times 10^{-7}$ & 0.319 \\
\hline 10 & 15 & 3 & 1500 & $\mathrm{AB}$ & $2.56 \times 10^{-7}$ & 0.322 \\
\hline 11 & 5 & 3 & 500 & $\mathrm{BC}$ & $3.24 \times 10^{-7}$ & 0.297 \\
\hline 12 & 10 & 1.5 & 1250 & $\mathrm{BC}$ & $1.04 \times 10^{-7}$ & 0.313 \\
\hline 13 & 10 & 3 & 500 & $\mathrm{AB}$ & $4.61 \times 10^{-7}$ & 0.287 \\
\hline 14 & 5 & 1 & 500 & $\mathrm{AB}$ & $5.74 \times 10^{-7}$ & 0.17 \\
\hline 15 & 5 & 1 & 1500 & $\mathrm{BC}$ & $6.50 \times 10^{-8}$ & 0.37 \\
\hline 16 & 5 & 1 & 1500 & $\mathrm{BC}$ & $7.71 \times 10^{-8}$ & 0.335 \\
\hline 17 & 5 & 3 & 1500 & CA & $1.06 \times 10^{-7}$ & 0.226 \\
\hline 18 & 5 & 3 & 1500 & CA & $2.25 \times 10^{-7}$ & 0.308 \\
\hline 19 & 10 & 3 & 1500 & $\mathrm{BC}$ & $7.16 \times 10^{-8}$ & 0.336 \\
\hline 20 & 5 & 2 & 500 & CA & $4.25 \times 10^{-8}$ & 0.36 \\
\hline 21 & 10 & 2.5 & 1250 & CA & $1.08 \times 10^{-7}$ & 0.325 \\
\hline 22 & 12.5 & 2 & 750 & $\mathrm{BC}$ & $3.31 \times 10^{-7}$ & 0.365 \\
\hline 23 & 5 & 1 & 1000 & CA & $3.96 \times 10^{-7}$ & 0.22 \\
\hline 24 & 5 & 3 & 500 & $\mathrm{BC}$ & $3.73 \times 10^{-7}$ & 0.29 \\
\hline 25 & 7.5 & 2 & 1000 & $\mathrm{AB}$ & $4.51 \times 10^{-7}$ & 0.239 \\
\hline 26 & 15 & 1 & 1500 & $\mathrm{BC}$ & $1.45 \times 10^{-7}$ & 0.293 \\
\hline 27 & 10 & 1.5 & 750 & CA & $2.16 \times 10^{-7}$ & 0.33 \\
\hline 28 & 10 & 1 & 500 & $\mathrm{BC}$ & $2.01 \times 10^{-7}$ & 0.327 \\
\hline
\end{tabular}




\section{Results and Discussion}

\subsection{Statistical Analysis and Development of an Empirical Model}

The statistical ANOVA results for SWR are presented in Table 4. From the ANOVA, the $F$-value of 54.04 suggests that the model is passable for effectively modeling SWR. Moreover, the model's "Prob $>F^{\prime}$ " values for all of the parameters are $<0.0005$. The coefficient of determination $\left(R^{2}\right)$ for the coefficient of friction is $98.92 \%$ and the adjusted coefficient of determination (Adj. $R^{2}$ ) is $97.09 \%$, which indicates that the experimental data are sensible and the relationship produced is agreeable. Moreover, model validation analysis was performed using a normal probability plot. The response of the normal plot for the coefficient of friction is shown in Figure $3 \mathrm{a}$ and seems to be normally distributed, and it is similar to a straight line, which denotes settled significance between the models. Furthermore, it can be observed that the residuals set against with predicted plots are normally distributed.

Table 4. Analysis of variance for SWR.

\begin{tabular}{ccccccc}
\hline Source & Sum of Squares & DOF & Mean Square & F-Value & Prob > F & Remarks \\
\hline Model & $1.03 \times 10^{-12}$ & 17 & $6.09 \times 10^{-14}$ & 54.04 & $<0.0001$ \\
A-Load & $3.11 \times 10^{-14}$ & 1 & $3.11 \times 10^{-14}$ & 27.61 & 0.0004 \\
B-Sliding velocity & $9.69 \times 10^{-14}$ & 1 & $9.69 \times 10^{-14}$ & 85.99 & $<0.0001$ \\
C-Sliding distance & $1.43 \times 10^{-13}$ & 1 & $1.43 \times 10^{-13}$ & 127.6 & $<0.0001$ \\
D-Composites & $4.51 \times 10^{-13}$ & 2 & $2.25 \times 10^{-13}$ & 200.13 & $<0.0001$ \\
AB & $9.02 \times 10^{-14}$ & 1 & $9.02 \times 10^{-14}$ & 80.05 & $<0.0001$ \\
AC & $3.73 \times 10^{-14}$ & 1 & $3.73 \times 10^{-14}$ & 33.08 & 0.0002 \\
AD & $1.36 \times 10^{-13}$ & 2 & $6.81 \times 10^{-14}$ & 60.41 & $<0.0001$ \\
BC & $9.73 \times 10^{-15}$ & 1 & $9.73 \times 10^{-15}$ & 8.63 & 0.0148 \\
BD & $1.37 \times 10^{-13}$ & 2 & $6.86 \times 10^{-14}$ & 60.83 & $<0.0001$ \\
CD & $1.65 \times 10^{-13}$ & 2 & $8.29 \times 10^{-14}$ & 73.55 & $<0.0001$ \\
A & $9.51 \times 10^{-14}$ & 1 & $9.51 \times 10^{-14}$ & 84.37 & $<0.0001$ \\
C & $5.32 \times 10^{-14}$ & 1 & $5.32 \times 10^{-14}$ & 47.19 & $<0.0001$ \\
Residual & $1.12 \times 10^{-14}$ & 10 & $1.12 \times 10^{-15}$ & & 0.5951 \\
Lack of Fit & $5 \times 10^{-15}$ & 5 & $1 \times 10^{-15}$ & 0.79 & Not significant \\
Pure Error & $6.27 \times 10^{-15}$ & 5 & $1.25 \times 10^{-15}$ & & \\
Cor. Total & $1.04 \times 10^{-12}$ & 27 & & & Adj. $R^{2}=97.09 \%$ & \\
& $R^{2}=98.92^{2} \%$ & & & &
\end{tabular}

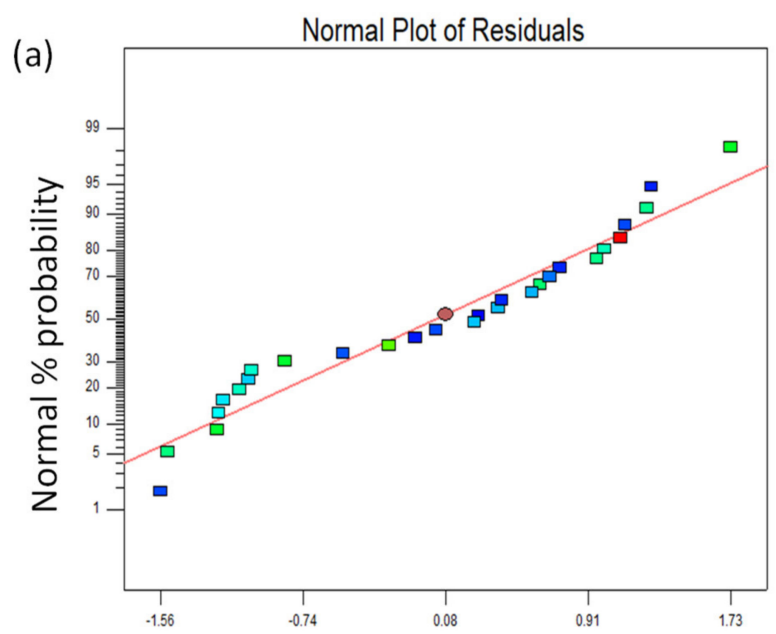

Internally Studentized Residuals

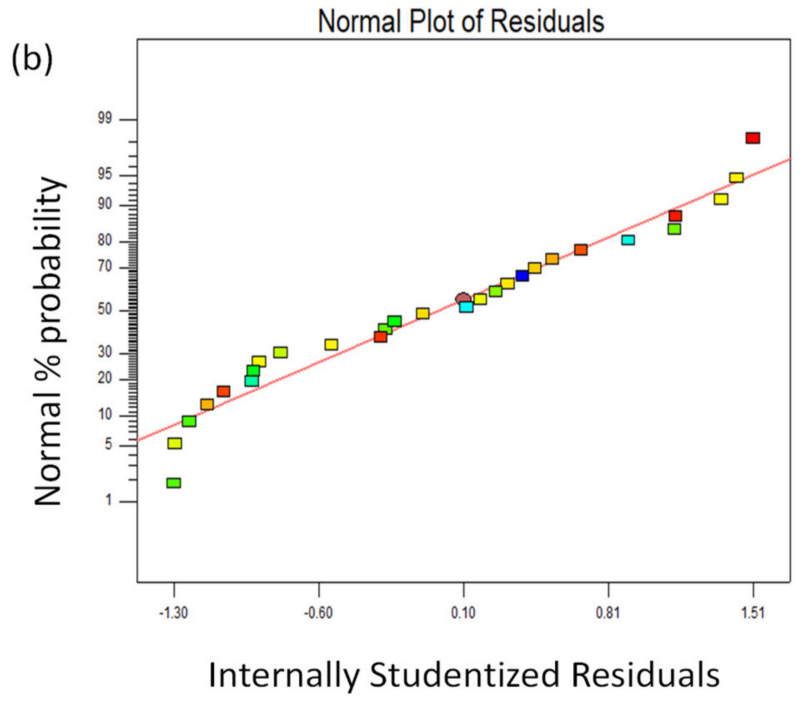

Figure 3. Normal probability plot of residuals for each response: (a) SWR; (b) COF. 
The statistical ANOVA results for COF are presented in Table 5. From the ANOVA, the $F$-value of 9.9335 suggests that the model is passable for effectively modeling the coefficient

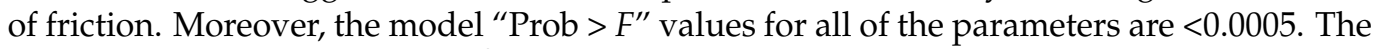
coefficient of determination $\left(R^{2}\right)$ for the coefficient of friction is $94.40 \%$ and the adjusted coefficient of determination (Adj. $R^{2}$ ) is $84.90 \%$, which indicates that the experimental data are sensible and the relationship produced is agreeable. Moreover, model validation analysis was performed using a normal probability plot. The response of the normal plot for the coefficient of friction is shown in Figure $3 \mathrm{~b}$ and seems to be normally distributed, and it is similar to a straight line, which denotes settled significance between the models. Furthermore, the residuals set against with predicted plots are normally distributed. Hence, the developed mathematical models can be effectively utilized for further investigations, and there is no motive to insure any desecration of independence [23].

Table 5. Analysis of variance for the coefficient of friction (ANOVA).

\begin{tabular}{|c|c|c|c|c|c|c|}
\hline Source & Sum of Squares & DOF & Mean Square & $F$-Value & Prob $>F$ & Remarks \\
\hline Model & 0.057 & 17 & 0.003 & 9.933 & 0.0004 & Significant \\
\hline A-Load & 0.002 & 1 & 0.002 & 8.082 & 0.0175 & \\
\hline B-Sliding velocity & 0.001 & 1 & 0.001 & 4.728 & 0.0458 & \\
\hline C-Sliding distance & 0.000 & 1 & 0.000 & 1.957 & 0.0192 & \\
\hline D-Composites & 0.009 & 2 & 0.004 & 13.884 & 0.0013 & \\
\hline $\mathrm{AB}$ & 0.000 & 1 & 0.000 & 1.515 & 0.0246 & \\
\hline $\mathrm{AC}$ & 0.009 & 1 & 0.009 & 26.680 & 0.0004 & \\
\hline $\mathrm{AD}$ & 0.014 & 2 & 0.007 & 20.826 & 0.0003 & \\
\hline $\mathrm{BC}$ & 0.000 & 1 & 0.000 & 1.577 & 0.0237 & \\
\hline $\mathrm{BD}$ & 0.004 & 2 & 0.002 & 6.284 & 0.0171 & \\
\hline CD & 0.005 & 2 & 0.002 & 8.414 & 0.0072 & \\
\hline $\mathrm{A}^{2}$ & 0.002 & 1 & 0.002 & 6.931 & 0.0250 & \\
\hline $\mathrm{B}^{2}$ & 0.004 & 1 & 0.004 & 14.124 & 0.0037 & \\
\hline$C^{2}$ & 0.004 & 1 & 0.004 & 13.550 & 0.0042 & \\
\hline Residual & 0.003 & 10 & 0.000 & & & \\
\hline Lack of Fit & 0.001 & 5 & 0.000 & 0.520 & 0.7547 & Not significant \\
\hline Pure Error & 0.002 & 5 & 0.000 & & & \\
\hline \multirow[t]{2}{*}{ Cor.Total } & 0.060 & 27 & & & & \\
\hline & $R^{2}=94.4$ & & \multicolumn{2}{|c|}{ Adj. $R^{2}=84.9 \%$} & & \\
\hline
\end{tabular}

\subsection{Influence of the Process Parameters on the Wear Characteristics} Influence on $S W R$

From the statistical analysis, it was found that the selected parameters have a significant influence on SWR. The significant variations of SWR with respect to the loading conditions of the three different composites are presented in the interaction plots (Figure $4 a-c)$. The influence of the load conditions and the different composite laminates on SWR are presented in Figure 4a. From the plot, it can be inferred that the wear rate of the composite laminates significantly increased with the increase of the applied load from 5 to $15 \mathrm{~N}$. It can be seen from the plot that the SWR of composite D1 (AB) seems to be prominent, followed by D2 (BC), whereas an improved wear resistance was found for composite D3 (CA). These can be attributed to the fact that the rate of wear increases in a non-linear fashion from standard to severe, and this growing trend was observed under different load conditions. Similar trends were observed in the adhesive wear properties of an aluminum hybrid metal matrix composites at a higher temperature, where their rate of wear increased in a non-linear fashion under high-velocity conditions [24]. 

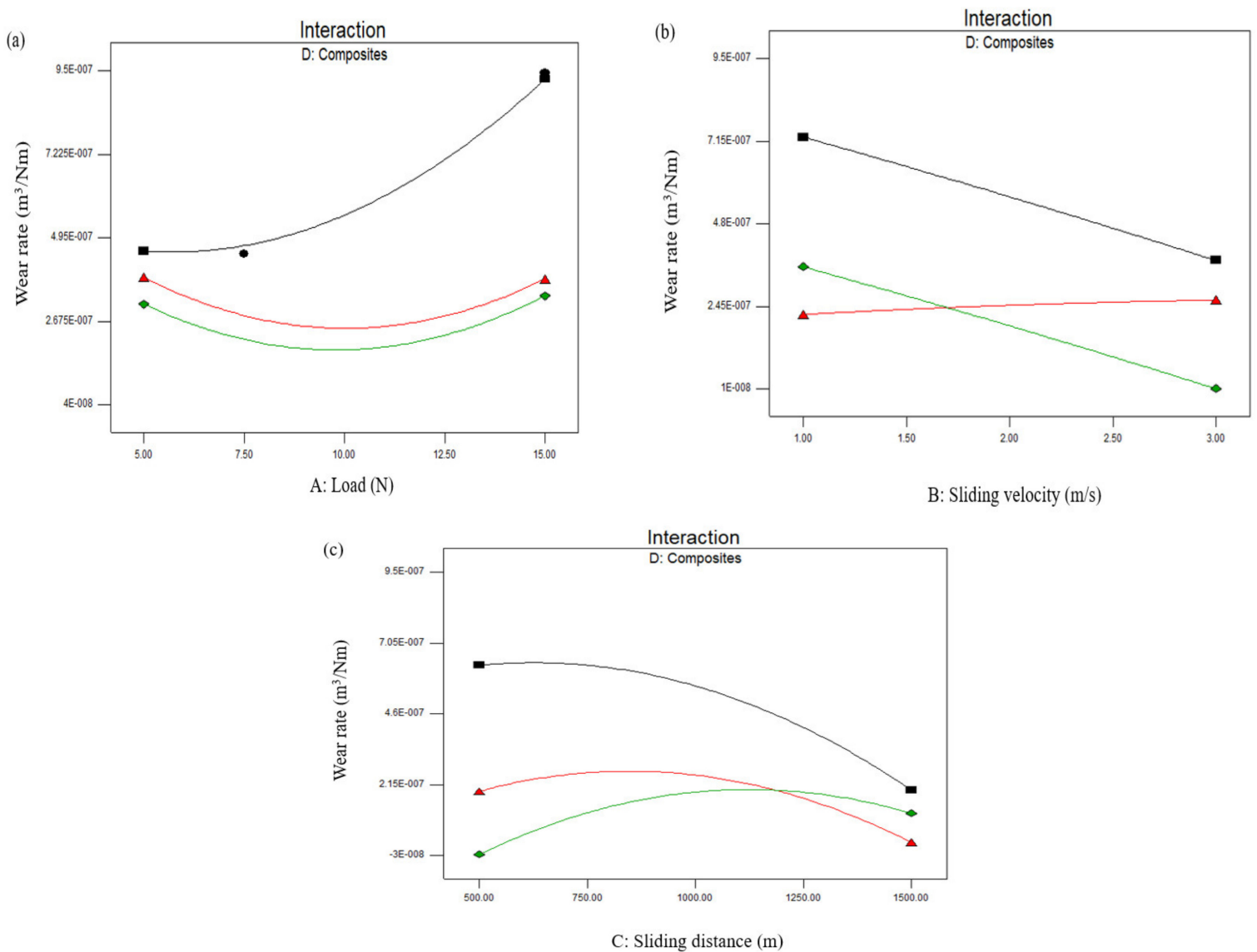

Figure 4. Two-dimensional interaction plots for the specific wear rate: (a) Wear rate vs. load; (b) wear rate vs. sliding velocity; (c) wear rate vs. sliding distance. (Composite combinations AB-Black; AC-Green; and BC-Red).

The impact of sliding velocity and the composite combinations on SWR are depicted in Figure $4 \mathrm{~b}$. From the interaction plot, it is evident that the SWR of composite combinations $\mathrm{D} 1 \mathrm{AB}$ ) and $\mathrm{D} 3 \mathrm{AC}$ ) slightly decreased with the increase in sliding velocity, whereas the SWR of composite D2 (BC) was found to be constant throughout the sliding velocity from 1 to $3 \mathrm{~m} / \mathrm{s}$. The influence of sliding distance and different composite combinations on $S W R$ are shown in the interaction plot in Figure 4c. From the plot, it can be observed that composite D3 (CA) exhibited an improved wear resistance with minimized SWR at a lower sliding speed. This could be due to the fact that hard-reinforced particles protruded at the specimen surface and bumped into the counterface at a lower sliding distance, and greater removal of the material was observed. Moreover, it can be seen that the wear rate slightly decreased with the increase in sliding distance for composite combinations D1 (AB) and D2 (BC).

Hence, it is desirable to decrease the sliding distance to improve the quality of cut through decreasing the SWR. The percentage of all three composites $(\mathrm{AB}, \mathrm{BC}$, and $\mathrm{CA})$ led to a sensible decline in the rate of wear rate, as displayed in Figure $4 \mathrm{a}-\mathrm{c}$. Similar to our present findings, an enhanced hardness increment on the polyether ether ketone matrix generated enhanced the resistance in the wear and seizure materials [21].

The response surface plots of composite D3 (CA) are displayed in Figure 5a,b, displaying the interface effect of diverse processing conditions on SWR. The influence of sliding velocity and load on SWR are presented in Figure 5a. It can be observed from the plot that the $S W R$ of the hybrid composite significantly increased with the rise of both variables. However, the minimized SWR was experiential for combinations of a lower loading condition $(5 \mathrm{~N})$ and a higher sliding velocity $(3 \mathrm{~m} / \mathrm{s})$. 

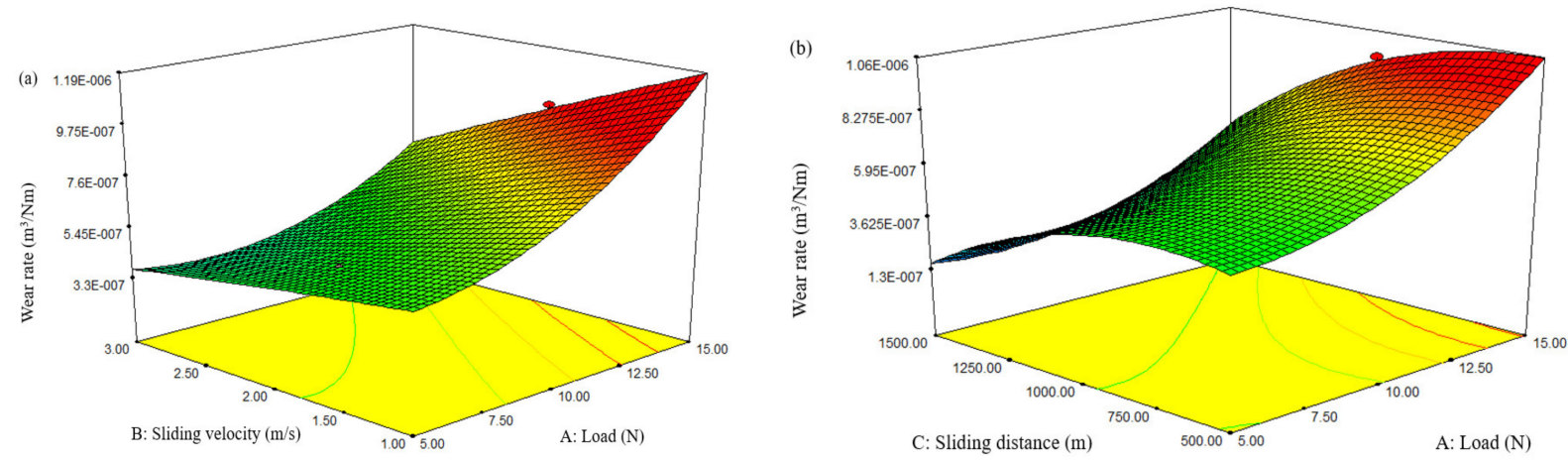

Figure 5. 3D response surface plots for the wear rate: (a) Load vs. sliding velocity; (b) load vs. sliding distance.

The impact of sliding distance and load on the SWR of composite D3 (CA) are described in Figure 5b. The plot shows that the SWR of the hybrid composites drastically increased with the upsurge of load and sliding distance. This could be attributed to the oxidation of composites during high loading conditions. During higher loading conditions, the frictional force between the disk and test specimens increase, which leads to an augmented SWR [21].

\section{Influence on $\mathrm{COF}$}

The statistical validation results indicate that the selected wear and composite variables have a substantial impact on COF. Figure $6 \mathrm{a}-\mathrm{c}$ indicates the interaction influence of the process parameters and various combinations of fabricated laminates on COF. The influence of the applied load and the composite combinations on COF are depicted in Figure 6a. The interaction plot indicates that COF increased with the increase in load for the composite $\mathrm{D} 1 \mathrm{AB})$, whereas there was no obvious change in the COF for the other two composite combinations. As the load increased, the area of contact between the pin and disk increased and, hence, COF also increased. The minimal COF was found at lower loading condition $(5 \mathrm{~N})$ for the $\mathrm{D} 1 \mathrm{AB})$ composite.

The influence of sliding velocity and the composite combinations on COF are presented in Figure $6 \mathrm{~b}$. The plot clearly indicates that COF slightly increased with the increase in sliding velocity for all three combinations of composites. However, a minimal COF was observed for composite D3 (CA). This is due to the fact that increasing the friction coefficient with sliding velocity leads to increased adhesion of the counterface material (pin) on the disk [21]. The variation of COF with respect to the sliding distance for different composites is presented in Figure 6c. The interaction plot indicates that there was no obvious change in COF for the composites. However, composites D1 (AB) and D3 (CA) exhibited lower COFs compared to composite $\mathrm{D} 2(\mathrm{BC})$. This is mainly because the matrix layer of $\mathrm{D} 1(\mathrm{AB})$ and $\mathrm{D} 3$ (CA) contacts the load carried by these fiber matrices, and also, COF declined compared to D2 (BC). The effectiveness of COF rests on the amount of load carried by the matrix/matrix, fiber/matrix, and fiber/fiber contacts and their respective COFs.

From the interaction plots, it was found that composite D3 (CA) exhibited lower COF, which is similar to the wear rate. Therefore, composite D3 (CA) was selected for further investigation. The 3D response surface plots shown in Figure 7a,b indicate the influence of the dry sliding parameters on the COF of composite combination D3 (CA). The consequence of sliding velocity and load on COF is presented in Figure 7a. It can be observed from the plot that COF linearly increased with respect to the applied load, whereas there was no significant variation in the sliding velocity. However, a lower COF was observed at lower values of load $(5 \mathrm{~N})$ and sliding velocity $(1 \mathrm{~m} / \mathrm{s})$. The increase in frictional coefficient with the increase in load rate was mainly due to the upsurge of adhesion strength. Generally, in many composite pairs, $C O F$ is low at the lower loads and a transition arises to a higher rate as the normal load increases [25]. 

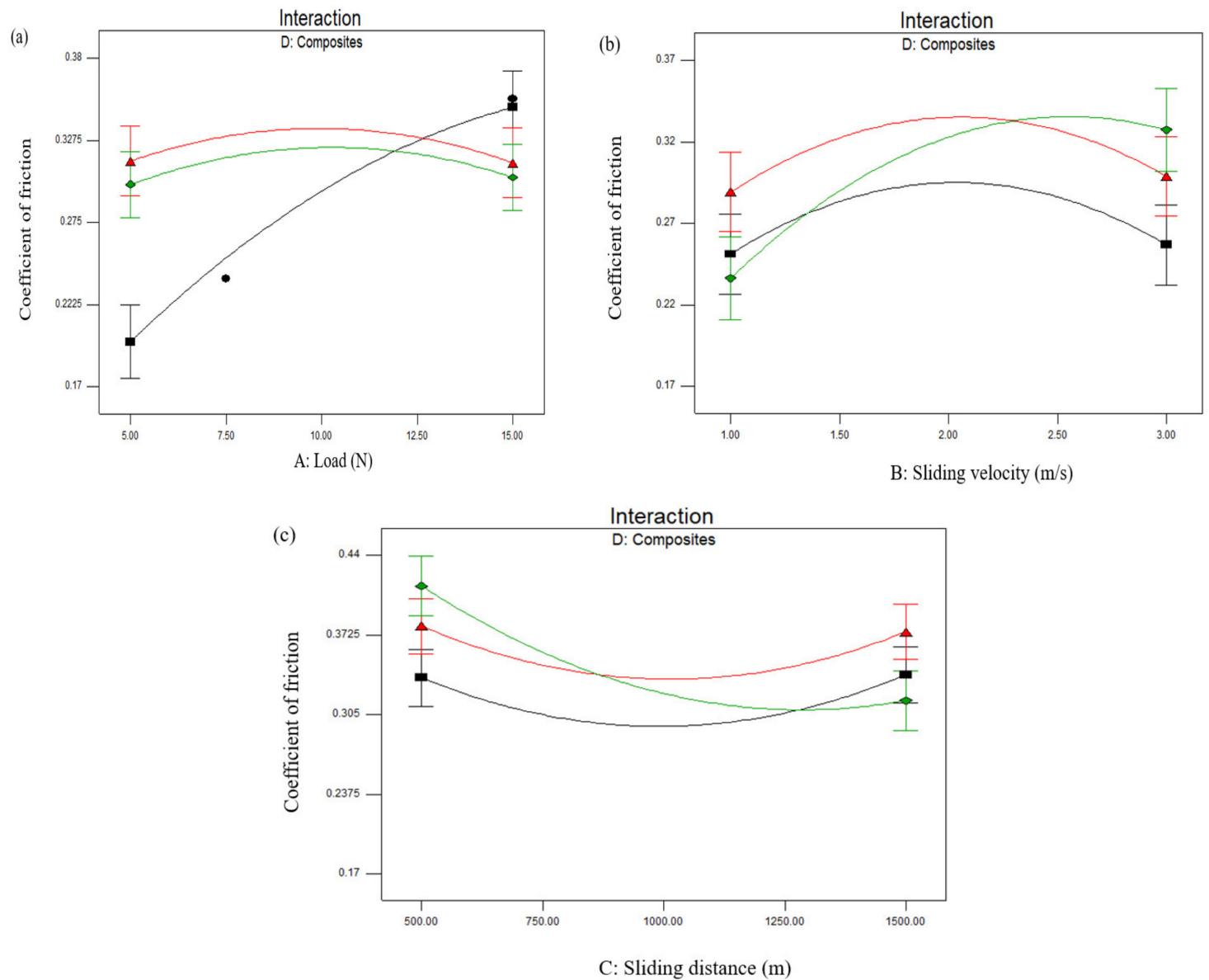

Figure 6. Two-dimensional interaction plots for COF: (a) Load vs. COF; (b) sliding velocity vs. COF; (c) sliding distance vs. COF. (Composite combinations AB-Black; AC-Green; and BC-Red).
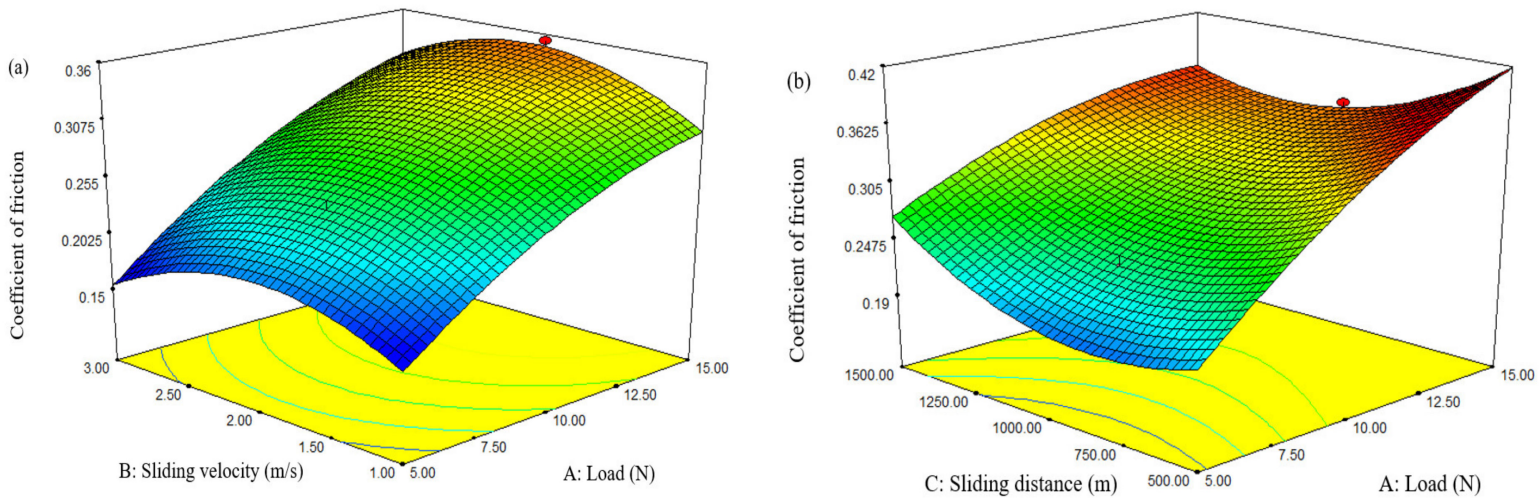

Figure 7. 3D response surface plots for COF: (a) Load vs. sliding velocity; (b) load vs. sliding distance.

Similarly, the consequences of sliding distance and load on COF are displayed in Figure $7 \mathrm{~b}$, which indicates that the increase in load rate and sliding distance from lower to higher values increases COF to maximum values. The augmented $C O F$ is experienced as a result of frictional heat, which is produced at countersurfaces at a higher loading condition. A simultaneous improvement in the applied load with sliding distance will improve the frictional force at the contact surface, and hence, $C O F$ will increase. However, a lower $C O F$ was found at a lower load $(5 \mathrm{~N})$ and sliding distance $(500 \mathrm{~m})$. From the investigations, it is observed that the COF of hybrid composites can be minimized by reducing the applied load, sliding velocity, and sliding distance. 


\subsection{Microstructural Analysis of Worn-Out Surfaces}

Microstructure screening of worn-out surfaces can deliver a better vison of the quality of fabricated hybrid composites with respect to different compositions and working conditions. The microstructures of worn-out surfaces were investigated using a scanning electron microscope (model: Sigma 300, Carl Zeiss, Oberkochen, Germany) with an accelerating peak power of 9-15 keV. The scanning electron microscopic (SEM) images of three different bio composites $(\mathrm{AB}, \mathrm{BC}$, and $\mathrm{CA})$ with various processing conditions are displayed in Figure $8 \mathrm{a}$,d. From the experimental investigations, it was found that composite CA delivered a significant wear resistance characteristic, and it was screened for SEM analysis under various processing conditions. Figure $8 \mathrm{a}, \mathrm{b}$ indicate a worn-out surface of composite $\mathrm{CA}$ at a testing condition of a $5 \mathrm{~N}$ load, a $1 \mathrm{~m} / \mathrm{s}$ sliding velocity, and a $500 \mathrm{~m}$ sliding distance. The micrographs show a minimal plow up track, micro-striation pattern, and smooth surface with reduced voids and pores, which indicates the eventual bonding between the reinforced and matrix materials. Balan et al. [26] found that the SEM images of epoxy-based hybrid composites demonstrated stable bonding and compatibility between the matrix and reinforced materials, with small fissures originating at the plastic particle interface and the matrix. Figure 8c,d show the SEM micrographs of wear surfaces of the composite combination CA at an operating condition of a $15 \mathrm{~N}$ load, a $3 \mathrm{~m} / \mathrm{s}$ sliding velocity, and a $1500 \mathrm{~m}$ sliding distance. It is evident from the micrographs that long pits and grooves, delamination, and fiber breakout with deep striation patterns occur at higher loading conditions. As the applied load increases, the wear characteristics of the fiber composites varies from abrasion to delamination, as apparent from the surface morphologies. The initiation of cracks and delamination at the interface of the particulates lead to de-bonding and pits formation [26]. The deformation of the composite surface increases due to the higher relative motion between the pin and disk, which significantly increases the wear rate of composites under higher loading conditions.
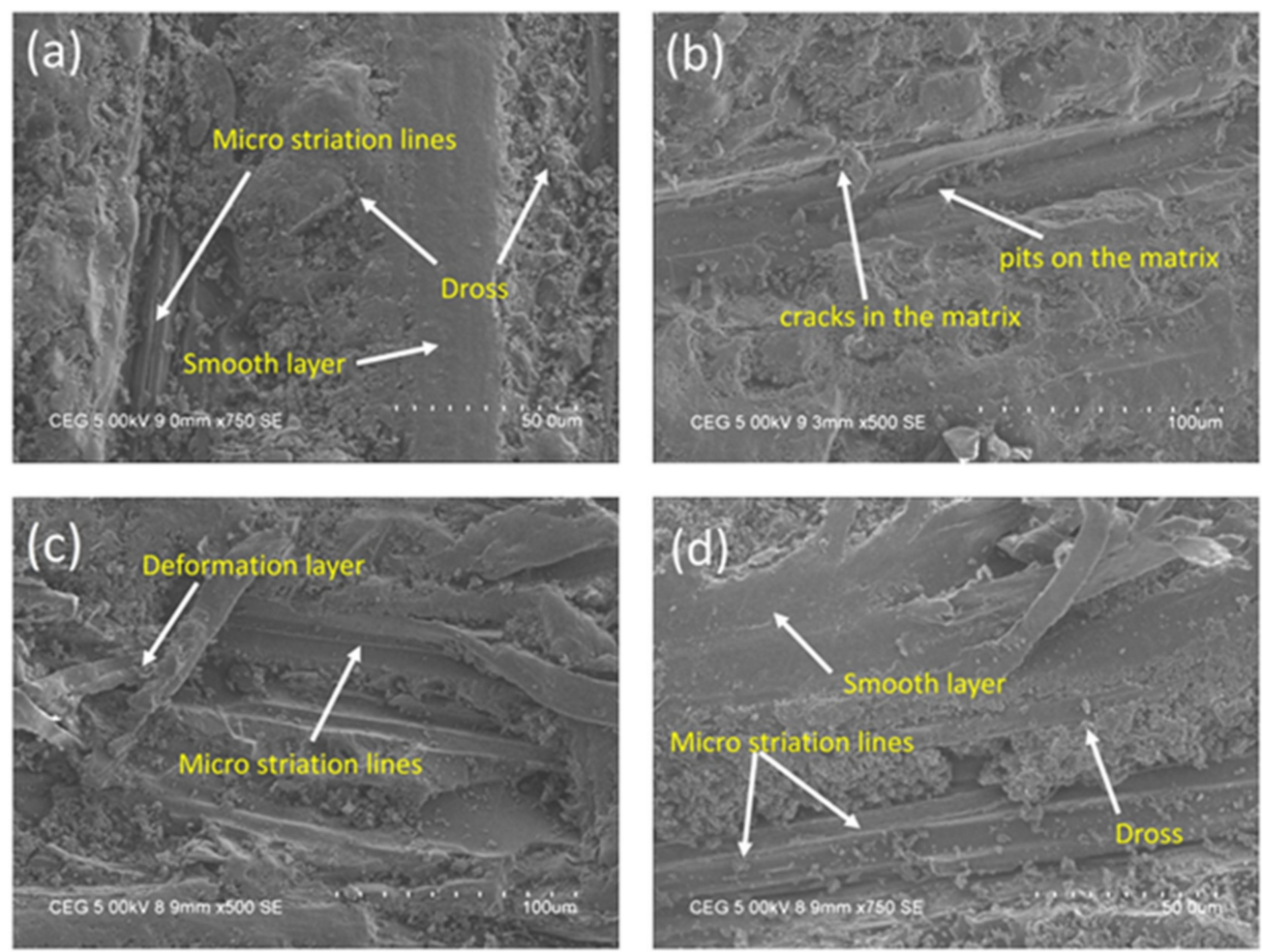

Figure 8. The SEM analysis of worn-out specimens at different wear testing conditions: $(\mathbf{a}, \mathbf{b})$ Load of $5 \mathrm{~N}$, sliding velocity of $1 \mathrm{~m} / \mathrm{s}$, and sliding distance of $500 \mathrm{~m} ;(\mathbf{c}, \mathbf{d})$ load of $15 \mathrm{~N}$, sliding velocity of $3 \mathrm{~m} / \mathrm{s}$, and sliding distance of $1500 \mathrm{~m}$. 


\subsection{Prediction of Optimal Process Variables Using GRA}

The goal of this research was to improve the wear properties of cast-off hybrid composite laminates by reducing SWR and COF. With the help of Equation (1) in GRA, the response variables were first normalized based on "the smaller, the better the conditions." Equation (2) was used to calculate the GRC values, and the grey relational grade (GRG) values were calculated by allocating equal weight to each of the responses studied in this study.

The obtained GRG of SWR and COF for different experimental runs are mentioned in Table 6. The fraction between the comparability and sequence of reference was defined using GRG. The optimal processing variable combination was obtained through taking the mean of the GRG values. The maximum grey relational grade of 0.7853 was obtained in the 17th run (Rank I) and it is significant with other grey relational grades. The corresponding process parameters, such as of composite combination of D1 (CA), i.e., a load of $5 \mathrm{~N}$, a sliding velocity of $3 \mathrm{~m} / \mathrm{s}$, and a sliding distance of $1500 \mathrm{~m}$, were considered optimal parameters of the composites for obtaining improved wear properties. A graphical representation of the obtained GRG for various experimental runs is presented in Figure 9.

Table 6. Calculation of grey relational coefficients and grey grades.

\begin{tabular}{|c|c|c|c|c|}
\hline \multirow{2}{*}{ Run } & \multicolumn{2}{|c|}{ Grey Relational Coefficient } & \multirow{2}{*}{ Grey Relational Grade } & \multirow{2}{*}{ Rank } \\
\hline & SWR & COF & & \\
\hline 1 & 0.5865 & 0.3892 & 0.4879 & 25 \\
\hline 2 & 0.3334 & 0.3464 & 0.3399 & 28 \\
\hline 3 & 0.9155 & 0.5039 & 0.7097 & 4 \\
\hline 4 & 0.5373 & 0.3971 & 0.4672 & 27 \\
\hline 5 & 0.6940 & 0.3427 & 0.5184 & 23 \\
\hline 6 & 0.7662 & 0.4987 & 0.6324 & 12 \\
\hline 7 & 1.0064 & 0.4004 & 0.7034 & 5 \\
\hline 8 & 0.5974 & 0.4588 & 0.5281 & 20 \\
\hline 9 & 0.6463 & 0.3955 & 0.5209 & 22 \\
\hline 10 & 0.7182 & 0.3908 & 0.5545 & 18 \\
\hline 11 & 0.6366 & 0.4343 & 0.5355 & 19 \\
\hline 12 & 0.9401 & 0.4054 & 0.6728 & 9 \\
\hline 13 & 0.5303 & 0.4545 & 0.4924 & 24 \\
\hline 14 & 0.4656 & 1.0000 & 0.7328 & 2 \\
\hline 15 & 1.0285 & 0.3277 & 0.6781 & 8 \\
\hline 16 & 0.9999 & 0.3714 & 0.6857 & 7 \\
\hline 17 & 0.9355 & 0.6352 & 0.7853 & 1 \\
\hline 18 & 0.7448 & 0.4140 & 0.5794 & 15 \\
\hline 19 & 1.0127 & 0.3700 & 0.6914 & 6 \\
\hline 20 & 1.0866 & 0.3391 & 0.7129 & 3 \\
\hline 21 & 0.9327 & 0.3861 & 0.6594 & 10 \\
\hline 22 & 0.6307 & 0.3333 & 0.4820 & 26 \\
\hline 23 & 0.5756 & 0.6610 & 0.6183 & 13 \\
\hline 24 & 0.5936 & 0.4483 & 0.5210 & 21 \\
\hline 25 & 0.5366 & 0.5856 & 0.5611 & 17 \\
\hline 26 & 0.8630 & 0.4422 & 0.6526 & 11 \\
\hline 27 & 0.7567 & 0.3786 & 0.5676 & 16 \\
\hline 28 & 0.7780 & 0.3831 & 0.5805 & 14 \\
\hline
\end{tabular}




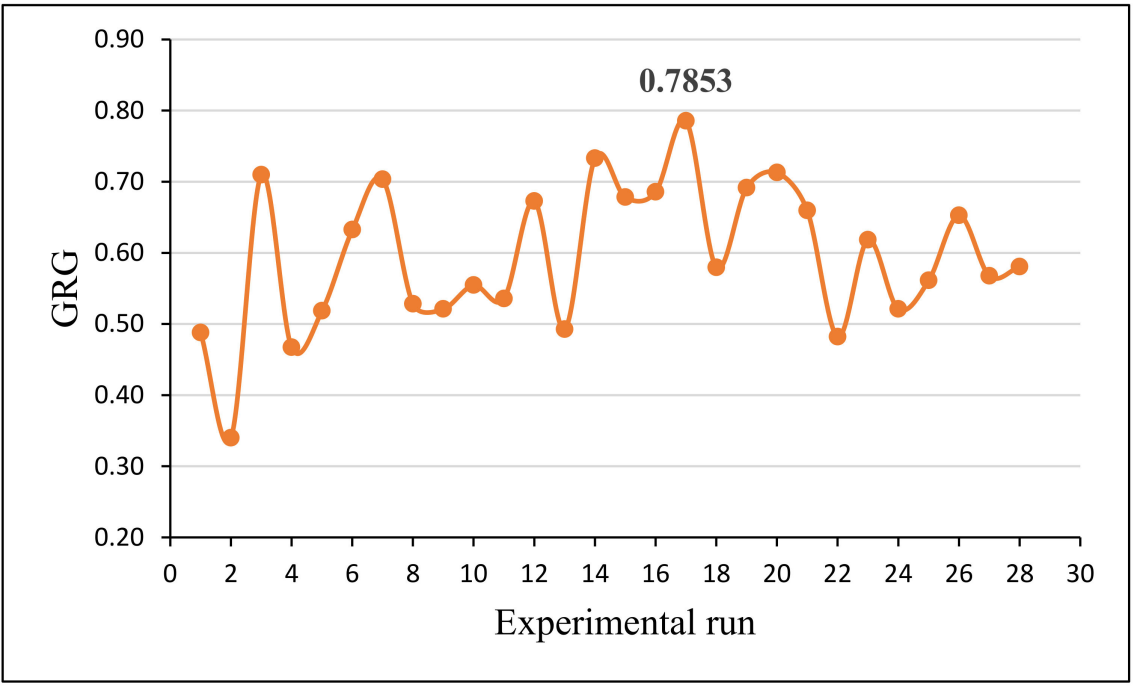

Figure 9. Graphical representation of the obtained grey relational grade for each experimental run.

\section{Conclusions}

The present investigation aimed to envisage the dry sliding wear characteristics of fabricated hybrid polymer matrix composites of three different compositions: $\mathrm{AB}$-aloe vera and bamboo; $\mathrm{BC}$ - bamboo and palm; and CA—palm and aloe vera. The results of the experimental, modeling, and optimization studies are as follows:

- The dry sliding wear test experiments were designed and executed through a Doptimal design approach. The ANOVA results displayed that the proposed quadratic mathematical models are efficient at 95\% conformance levels in the prediction of wear behaviors of fabricated composites with a coefficient of determination of $98.92 \%$ for SWR and $97.09 \%$ for COF.

- From the ANOVA and interaction results, composite D3 (CA) showed improved wear resistance due to improved interfacial bonding and stacking sequence, even at higher loads and sliding conditions. Moreover, the sliding distance was found to be more significant parameters for a specific wear rate, whereas the applied load and sliding distance were found to be significant for COF.

- $\quad$ Based on the RSM-GRA hybrid approach, the optimal parameter combinations for improved wear properties were obtained and are as follows: Composite combinations of D3 (CA), a load of $5 \mathrm{~N}$, a sliding velocity of $3 \mathrm{~m} / \mathrm{s}$, and a sliding distance of $1500 \mathrm{~m}$ with a maximum GRG of 0.7853 .

- $\quad$ SEM micrographs revealed the micro-striation patterns and fiber delamination of worn-out surfaces under various testing conditions.

- It is proposed that the hybrid approach of RSM-GRA can be effectively utilized for the modeling and optimization of the wear properties of hybrid polymer matrix composites with minimal computational effort within the selected limits of processing conditions.

- $\quad$ Future perspectives of the present research may enlighten the investigation of thermal and dynamic properties of the composites with different orientations and stacking methods.

Author Contributions: Conceptualization, B.M., B.M.V.R. and D.R.; methodology, B.M., B.M.V.R., D.R. and A.A.; design of experiments, B.M. and D.R.; experimental setup, B.M.; experiments, B.M. and D.R.; measurements, B.M., D.R., A.A. and E.A.N.; investigation, B.M., B.M.V.R., D.R., A.A. and E.A.N.; resources, B.M., B.M.V.R., D.R., A.A., H.M. and E.A.N.; visualization, B.M., D.R., A.A., H.M. and E.A.N.; writing-original draft preparation, B.M., D.R., A.A., H.M. and E.A.N.; writing-review and editing, B.M., B.M.V.R., D.R., A.A., H.M. and E.A.N.; supervision, B.M., B.M.V.R., D.R., A.A., H.M. and E.A.N.; project administration, B.M. and D.R.; funding acquisition A.A., E.A.N. and D.R. All authors have read and agreed to the published version of the manuscript. 
Funding: The authors extend their appreciation to the Researchers Supporting Project (RSP-2021/164), King Saud University, Riyadh, Saudi Arabia, for financially supporting this research work.

Institutional Review Board Statement: Not applicable.

Informed Consent Statement: Not applicable.

Data Availability Statement: Data is contained within the article.

Acknowledgments: The authors extend their appreciation to the Researchers Supporting Project (RSP-2021/164), King Saud University, Riyadh, Saudi Arabia, for financially supporting this research work.

Conflicts of Interest: The authors declare that they have no conflicts of interest. The funders had no role in the design of the study; in the collection, analyses, or interpretation of data; in the writing of the manuscript, or in the decision to publish the results.

\section{References}

1. Sastra, H.Y.; Siregar, J.P.; Sapuan, S.M.; Hamdan, M.M. Tensile Properties of Arenga pinnata Fiber-Reinforced Epoxy Composites. Polym. Plast. Technol. Eng. 2007, 45, 149-155. [CrossRef]

2. Leman, Z.; Sapuan, S.M.; Azwan, M.; Ahmad, M.M.H.M.; Maleque, M.A. The Effect of Environmental Treatments on Fiber Surface Properties and Tensile Strength of Sugar Palm Fiber-Reinforced Epoxy Composites. Polym. Plast. Technol. Eng. 2008, 47, 606-612. [CrossRef]

3. Uyup, M.K.A.; Paridah, M.T.; Husain, H.; Sapuan, S.M.; Bakar, E.S. Effect of curing time on physical and mechanical properties of phenolic-treated bamboo strips. Ind. Crops Prod. 2009, 29, 214-219.

4. Sapuan, S.M.; Harimi, M.; Maleque, M.A. Mechanical Properties of Epoxy/Coconut Shell Filler Particle Composites. Arab. J. Sci. Eng. 2003, 28, 171-181.

5. Rashdi, A.A.A.; Sapuan, S.M.; Ahmad, M.M.H.M.; Khalina, A. Water absorption and tensile properties of soil buried kenaf fibre reinforced unsaturated polyester composites (KFRUPC). J. Food Agric. Environ. 2009, 7, 4-7.

6. Jawaid, M.; Abdul Khalil, H.P.S.; Abu Bakar, A. Woven hybrid composites: Tensile and flexural properties of oil palm-woven jute fibres-based epoxy composites. Mater. Sci. Eng. A 2011, 528, 5190-5195. [CrossRef]

7. Kumar, N.R.; Chandra, R.B. Retention of Mechanical and Thermal Properties of Hydrothermal Aged Glass Fiber-Reinforced Polymer Nanocomposites. Polym. Plast. Technol. Eng. 2018, 57, 1676-1686.

8. Nayak, R.K.; Ray, B.C. Influence of seawater absorption on retention of mechanical properties of nano-TiO2 embedded glass fiber reinforced epoxy polymer matrix composites. Arch. Civ. Mech. Eng. 2018, 18, 597-1607. [CrossRef]

9. Nayak, R.K.; Ray, B.C. Water absorption, residual mechanical and thermal properties of hydrothermally conditioned nano-Al2O3 enhanced glass fiber reinforced polymer composites. Polym. Bull. 2017, 74, 4175-4194. [CrossRef]

10. Narayanan, V.; ElayaPerumal, A.; Alavudeen, A.; Thiruchitrambalam, M. Mechanical and water absorption behaviour of banana/sisal reinforced hybrid composites. Mater. Des. 2011, 32, 4017-4021.

11. Tufan, M.; Akbas, S.; Aslan, M. Decay resistance, thermal degradation, tensile and flexural properties of sisal carbon hybrid composites. Maderas-Cienc. Tecnol. 2016, 18, 599-606. [CrossRef]

12. Wambua, P.; Vangrimde, B.; Lomov, S.; Verpoest, I. The response of natural fibre composites to ballistic impact by fragment simulating projectiles. Compos. Struct. 2007, 77, 232-240. [CrossRef]

13. Mishra, S.; Mohanty, A.K.; Drzal, L.; Misra, M.; Parija, S.; Nayak, S.K.; Tripathy, S.S. Studies on mechanical performance of biofibre/glass reinforced polyester hybrid composites. Compos. Sci. Technol. 2003, 63, 1377-1385. [CrossRef]

14. Abdul Khalil, H.P.S.; Hanida, S.; Kang, C.W.; Nik Fuaad, N.A. Agro-hybrid Composite: The effects on mechanical and physical properties of oil palm fiber (EFB)/glass hybrid reinforced polyester composites. J. Reinf. Plast. Compos. 2007, 26, 203-218. [CrossRef]

15. Chaudhary, V.; Bajpai, P.K.; Maheshwari, S. An Investigation on Wear and Dynamic Mechanical behaviour of Jute/Hemp/Flax Reinforced Composites and Its Hybrids for Tribological Applications. Fiber Polym. 2018, 19, 403-415. [CrossRef]

16. Shalwan, A.; Yousif, B. In state of art: Mechanical and tribological behaviour of polymeric composites based on natural fibres. Mater. Des. 2013, 48, 14-24. [CrossRef]

17. Sneha Latha, P.; Venkateswara Rao, M.; Kiran Kumar, V.V.; Raghavendra, G.; Ojha, S.; Inala, R. Evaluation of mechanical and tribological properties of bamboo-glass hybrid fibre reinforced polymer composite. J. Ind. Text. 2016, 46, 3-8. [CrossRef]

18. Karsli, N.G.; Aytac, A.; Deniz, V. Effects of initial fiber length and fiber length distribution on the properties of carbon-fiberreinforced-polypropylene composites. J. Reinf. Plast. Comp. 2012, 31, 1053-1060. [CrossRef]

19. Parikh, H.H.; Soni, H.P.; Suthar, D.A.; Patel, D.H. Mechanical and Tribological Characterization of Hybrid Natural Fiber Reinforced Composites. Curr. Mater. Sci. 2019, 12, 136-143. [CrossRef]

20. Shuhimi, F.F.; Bin Abdollah, M.F.; Kalam, M.A.; Masjuki, H.H.; Mustafa, A.; Amiruddin, H. Tribological Characteristics Comparison for Oil Palm Fibre/Epoxy and Kenaf Fibre/Epoxy Composites under Dry Sliding Conditions. Tribol. Int. 2016, 101, 247-254. [CrossRef] 
21. Rajmohan, T.; Palanikumar, K.; Davim, J.P.; Arun Premnath, A. Modeling and optimization in tribological parameters of polyether ether ketone matrix composites using D-optimal design. J. Thermoplast. Comp. 2014, 1-28. [CrossRef]

22. Rajamani, D.; Ziout, A.; Balasubramanian, E.; Velu, R.; Sachin, S.; Mohamed, H. Prediction and analysis of surface roughness in selective inhibition sintered high-density polyethylene parts: A parametric approach using response surface methodology-grey relational analysis. Adv. Mech. Eng. 2018, 10,1-16. [CrossRef]

23. Balasubramanian, E.; Rajamani, D.; Arunkumar, P. Modeling and prediction of optimal process parameters in wear behaviour of selective inhibition sintered high density polyethylene parts. Prog. Addit. Manufact. 2018, 3, 109-121.

24. Aravind, C.; Gopala Krishnan, S.; Radhika, N. Investigating the Adhesive Wear Properties of Aluminum Hybrid Metal Matrix Composites at Elevated Temperatures Using RSM Technique. Tribol. Ind. 2019, 41, 604-612. [CrossRef]

25. Nuruzzaman, D.M.; Chowdhury, M.A. Effect of Normal Load and Sliding Velocity on Friction Coefficient of Aluminum Sliding Against Different Pin Materials. Am. J. Mater. Sci. 2012, 2, 26-31. [CrossRef]

26. Sakthi-Balan, G.; Ganesh, N.; Ravichandran, M. Study of tribological and water intake characteristics of epoxy-based hybrid composite. Mater. Today 2020, 27, 729-735. 